\title{
Interpreting Advance Directives: Ethical \\ Considerations of the Interplay Between Personal and Cultural Identity
}

\author{
Silke Schicktanz
}

Published online: 8 May 2009

(C) The Author(s) 2009. This article is published with open access at Springerlink.com

\begin{abstract}
In many industrialized countries ethicists and lawyers favour advance directives as a tool to guarantee patient autonomy in end-of-life-decisions. However, most citizens seem reluctant to adopt the practice; the number of patients who have an advance directive is low across most countries. The article discusses the key argument for seeing such documents as an instrument of self-interpretation and life-planning, which ultimately have to be interpreted by third parties as well. Interpretation by third parties and the process of self-reflection are conceptually linked by a qualitative concept of identity. Identity is conceived here as constructed in a processual dialogue between a personal and a cultural perspective. How the cultural dimension comes into play in understanding the motivation, rejection or content of wished for end-of-lifedecisions, is shown by a brief review of empirical and cultural studies. Understanding advance directives as a culturally embedded tool of self-interpretation should help to overcome urgent moral problems in clinical settings: how to interpret such documents, how to deliberate on the content and on the best form.
\end{abstract}

Keywords Advance directives - Culture - Identity - Ethics of a good life . Moral desirability · Interpretation · Proxy

\section{Introduction}

Many doctors, ethicists, and lawyers presently perceive advance directives as tools for ensuring autonomy and enforcing personal wishes regarding medical treatment.

\footnotetext{
S. Schicktanz $(\bowtie)$

Department of Medical Ethics and History of Medicine, University Medical Center of Goettingen, Humboldtallee 36, 37073 Göttingen, Germany

e-mail: silke.schicktanz@medizin.uni-goettingen.de
} 
In recent years, governmental policies or national ethics committees have strengthened the binding character of advance directives in many countries [20]. Denmark, for e.g., has had specific legislation to stipulate advance directives since 1992, Israel since 2005, Austria since 2006, while in Germany there is currently a parliamentary debate on three bills differing in their answer to the question of how binding such documents should be. It is known, however, that advance directives (or so called 'living wills') pose serious practical and ethical problems related to continuity, liability, completeness, interpretation and the relationship between rejected and demanded medical treatments, all of which have been intensively discussed (see e.g., [6]).

This debate over advance directives is dominated by normative questions, embedded in both deontological and consequentialistic approaches. Advance directives are discussed as a tool for respecting the rights and interests of patients and raise the question of what duties physicians and others have towards such documents. Despite the controversies, it seems that the majority of medical ethicists, lawyers and physicians presently tend to regard advance directives as reasonable [21].

But one should keep in mind that the majority of the population in many western, highly industrialized countries does not currently hold an advance directive. Only $3-23 \%$ of people hold an advance directive according to studies in USA, Israel, Netherlands and Germany (see [21, 22, 26]). Why is this? The few studies done in this field suggest several reasons: a lack of information regarding the opportunity to create advance directives, fear of abuse by physicians [27] but also moral confusion and avoidance of 'negative thinking' [28].

These normative questions are neither solved nor obsolete. But for anybody who holds a very liberal position, centered on autonomy and oriented around negative freedom, it seems obvious that citizens should decide freely if they want to hold an advance directive or not. From this perspective, there seems no need for further discussion of why to compose and how to interpret an advance directive. In response to this position my first goal is here to investigate whether the writing of advance directives is relevant from an ethical perspective of seeking a good life and what implications this would have for their interpretation by third parties. My second, more profound goal is to show how concrete bioethical questions are intermingled with fundamental ideas of identity. However, concepts of identity require in turn a critical reflection on the relationship between the individual and society.

In the following, my argumentation is structured around four main topics. Firstly, I want to discuss the role of the ethics of a good life for advance directives, and here especially I want to explore identity as a central reference point. As a second issue, I will touch on the question how socio-cultural factors interplay with identity and personal attitudes, especially in this field. My third argument is that there is a need for higher sensitivity towards cultural identity because of its relevance in the interpretation of such documents by third parties. Finally, I will briefly sketch implications for current practice. 


\section{The Role of an Ethics of the Good Life for Advance Directives and Decision-Making}

Advance directives are documents which encompass preferences, values, and anticipated situations for end of life situations. They centre on defining a 'good death'. In the clinical setting they show great variety in the way they are composed: hand-written letters, filled-in pages of multiple choice questionnaires, video tapes etc. They result from a person's primary decision to draft such a document. As the survey of Sahm et al. [27] showed, being diagnosed with a life-threatening disease increases the tendency to concern oneself with end of life treatment. Here, 'being affected' means to gain specific experience (e.g., handle a cancer diagnosis) and to be confronted with concrete decisions (e.g., choice of medical treatment). But the status of being affected itself depends on epistemic and normative premises which can differ strongly [31]. For example, young healthy persons enjoying a risky life style (e.g., by hang gliding, or motor bicycling) may regard themselves as 'being affected' by end of life decisions because they are aware of being exposed to higher risks of life-threatening injuries. Therefore, the need for an advance directive is less justified by an objective status of being chronically ill or getting old as the study of Sahm et al. [27] may suggest. The need seems more likely be triggered by the individual wish to care about the own death and to clarify one's very personal ideas concerning the own body-in order of being reflective of one's own identity.

Decisions for or against an advance directive could thus be addressed in terms of moral desirability and questions of a good life. 'Ethics of a good life' is used here as an umbrella term which encompasses both virtue ethics as the ethical reflection of a morally meritorious life which is responsive to the demands of the world [17] as well as so called 'perfectionism' [16]. When we discuss 'ethics of a good life' we pay attention to a number of topics that have been mostly neglected by modern moral philosophy: virtues and moral character, moral education, moral wisdom or discernment, friendship and family relationships, a deep concept of happiness, the role of the emotions in our moral life and the fundamentally important questions of what sort of person $I$ should be and how we should live (see [17]). ${ }^{1}$ Therefore, ethics of a good life always encompasses an individual and a social dimension.

Life Planning and Ethical Deliberation About the Own Death: Handling Uncertainties and Self-Reflexivity

I follow here an approach that integrates two strands often separated in ethical theory: on the one hand normative ethical questions asking "What ought/shall someone do?", and on the other hand such ethical questions of a good life asking "What do I want to do?/How do I want to live?". I follow the idea, posed by various philosophers, that in modern life, moral reflection always encompasses these two questions, but depends on the prevailing context: in political dimensions and

\footnotetext{
${ }^{1}$ Here I cannot go into a more detailed analysis which of these topics are more important than others nor do I defend a specific strand of virtue ethics.
} 
questions of justice the 'ought' dimension prevails [10, 24], while in personal relationships and the family context "moral desirability and wisdom" prevails-as long as basic rights and interests of others are not harmed. For example, Habermas [10] classifies in his discourse ethics the first class of questions as 'moral questions' while those in the second class are 'ethical questions'. Other philosophers such as Krämer [18] and Haker [11] use German terms (Germ.: Sollensethik/Strebensethik) which may be translated as "ethics of ought" and "ethics of moral desirability in one's own life". The first notion encompasses deontological and consequentialistic approaches (and also some aspects of virtue ethics; see above), while the second encompasses personal virtues and relational, contextual approaches that refer to a meaningful life. Ethics - in its various dimensions - is here understood as reflection on morality as a set of practical norms and everyday life customs, a reflection that seeks for a justification why some actions and decisions are better than others.

At this point one may ask why a theoretical distinction of ethics of good life and ethics of ought has (or ought to have) any interest for bioethics, especially for advance directives.

One important reason stems from Rawls when he referred to the importance of rational life plans for a good life, a human well-being [24, §63]. According to this, normative reasoning does not only concern social questions of justice, distribution, rights and freedom but also how we rank our own wishes, interests and moral motives with respect to gain a rational plan, that is with full awareness of the relevant factors and after a careful consideration of the consequences. As Rawls puts it, "[t]he aim of deliberation is to find that plan which best organizes our activities and influences the formation of our subsequent wants so that our aims and interests can be fruitfully combined into one scheme of conduct" (410f). In this line of argumentation thinking about our own death in the context of modern clinical treatment could be seen as a reasonable way of handling the modern risk of uncertainty about what might happen to us in a situation where we depend on lifesustaining machines. This should be accepted as an important part of our way of life instead of criticizing it as narcistic behaviour or waste of time as the social philosophers Anthony Giddens correctly states: "Life planning in respect of the body is hence not necessarily narcissistic-like other aspects of reflexivity of selfidentity, body-planning is more often an engagement with the outside world than a defensive withdrawal from it" [8, p. 178]. To be clear about another distinction, this sort of ethical reasoning will not end in recommendations for laws and social policies but is part of self-reflexivity in modern societies.

Deontological questions such as "Is it morally acceptable to withdraw medical treatment or to commit suicide?" are to my understanding fundamental and are normatively paramount compared to an ethical reflection on "how do I want to die/ what is my perspective of a (morally) good death". But I understand the latter question as 'preceding' the context of planning one's decisions regarding the end of life-as precedent chronologically and in everyday life. Furthermore, questions of an ethics of ought and those of an ethics of a good life cannot be separated in defining the responsibilities of proxies because here personal values and virtues as trust and love define moral duties such as liability and responsibility (e.g., in the case "My son, whom I trust more than my daughter, should decide when the 
life-supporting treatment should be withdrawn when I am not able any more to communicate").

The question remains in which cases writing an advance directive could be indicated and what should be considered in the light of the above reflections. If I am convinced that dealing with illness and death in a near or remote future would have negative long-time impacts on my psyche, then good reasons are at hand not to formulate an advance directive (see [4]). On the other hand, specific considerations about my own notion of a good life can be a reason to formulate one because I have very specific expectations about my preferences and what I understand as a good death. But merely informing others about my concrete preferences could be in many clinical cases insufficient. Proxies, doctors, and lawyers often must interpret these documents, which means construing and assessing these wishes and preferences under new circumstances. Some people hold conceptions of illness, death, embodiment and care in the family, which are quite complex. Moreover, such considerations are always based on the respective cultural meaning of illness, death, and body, as many sociologists, ethnologists and anthropologists have convincingly demonstrated (see e.g., [15]) (see below). Hence, an individual explanation of our own reasons and cultural background assumptions (what I call here 'identity') is part of a positive conception of patient autonomy as it will reduce uncertainty, avoid misunderstandings, and provide a helping hand for interpretation in situations we cannot anticipate in detail.

\section{'Identity' as a Reference Point for the Relationship of a Person and Her Social Embedding}

On my understanding, 'identity' is a central anchor for all questions regarding the ethics of a good life. This is because exploring how one wants to be requires clarifying who one is.

There has been an exploding interest in identity in philosophy, sociology and political science in the last decade. At the same time, various voices have raised concerns and critiques regarding the concept of identity, mainly influenced by postmodern views or analytical approaches. In these positions "identity" is regarded as problematic because of its essentialistic connotations and its association with subjectivity and truth (see [12]). Thus, no one can take for granted what is meant by the term 'identity'. However, as the British sociologist Stuart Hall put it once, the concept of identity should be understood as something that is constituted within representation (language, discourses, cultural practice), not solely from outside [12, p. 4]: “...we need to understand them [identities] as produced in specific historical and institutional sites within discursive formations and practices, by specific enunciative strategies." Hall defends the need for identity in a better understanding how discourses, practice and social framework interact with subjectivity, psychological mechanisms and the self-positioning of subjects. For Hall, 'culture' and 'cultural identity' are necessary for understanding how the public (e.g., the audience of media/politics) give meaning to texts and messages. There is no passive reception but an active process of giving meaning, negotiation, and interpretation. I believe that this observation also has importance for the bioethical 
debate on advance directives: we should be aware that these are 'texts' which are composed and interpreted within cultural practices of interaction but that they are also a construct of a discoursive practice that induces identity.

Precisely this interaction is also an important reference point for many (if not all) ethical questions in applied ethics. In applied ethics and political philosophy we cannot renounce the debate about concepts of identity [25].

At this point one might ask why a theory of identity and society has, or ought to have, any ethical interest. Why not simply leave such theorizing to the sociologists and cultural theorists? One important answer is given by Charles Taylor in his analysis of the liberal-communitarian debate. Taylor [36, pp. 182ff] shows that the way how we conceptualize the relationship between the self, identity and society is closely linked to normative stances concerning basic ethical question such as rights and duties, freedom and solidarity etc. The ontological question, whether human agents are related to society more in an atomistic or more in a holistic way, hints at a core premise for understanding different moral points of view. To be more specific: bioethics, too, relies_-just as political philosophy—on anthropological and ethical premises. Because we cannot do without 'identity' a critical reflection on the conditions for defining and constructing categories of identity is needed.

At this point, I favour an interpretation of identity that aims at defining it as a qualitative concept [25, p. 69]. This concept of personal identity, as suggested by Taylor [33], is based on developmental-psychological and social-psychological, cultural as well as linguistic-pragmatic assumptions. It designates a practical selfimage, that assumes that the question "What person am I?" comes along with the question "What community/group are we?". This correspondence of personal and socio-cultural identity is established during the shared implementation of social interaction. Identity is conceptualized as a processual, reflexive and intersubjectively constituted development. Competing interpretations of identity may exist. They are assessed, re-interpreted and weighted by the individual during the course of his or her life. 'Identity' itself could be seen as an object of negotiation and selfpositioning. This notion is most convincing for modern societies, as Anthony Giddens argues [8, 175ff]. Moreover, Giddens argues that it is rather implausible to believe that the individual is essentially passive in relation to overwhelming external social or cultural forces. But modern social life offers mixed opportunities. Traditional as well as modern cultural ways of life offer resources and various narratives which the human agent uses as possible models for their life plans-but not as fixed stories. Individuals are actively restructuring new forms of gender, family relations, religion, working place, healing etc. However, the role of such models, (or great narratives) or social frameworks should not be underestimated: If we intend to understand and to position ourselves it is necessary to identify these frameworks and to reflect on them.

The social framework that Charles Taylor deems so important for identity formation can be considered as "language" or "culture" [25, pp. 75f]. At this point I want to focus on culture, including communication and interpretation as an intrinsic part of language. Culture means here socially shared values and historically grown and culturally interpreted structures. These are expressed by affiliation to cultural institutions and ways of life as for example in religious communities, 
ethnicities, generations, political groups, nationalities or in daily social life. These ways of life can be distinguished by the fact that they offer explicit explanations of hermeneutic self-interpretation, i.e., in part answers to the question "what are we?". Charles Taylor provides for this purpose the metaphor of culture as a moralcognitive topography. Social forms of life and institutions always include implicit and unarticulated ideas, interpretations or explanations for differentiations between important and unimportant, good and bad, nature, the position of human beings in the community, the role of knowledge, etc. [33]. The same point on identity-but more concretely-emerges from Appiah [1] in his work on identity, political liberalism and moral philosophy. Appiah argues very well how social 'identity' should be understood in a process between the individual and his cultural embeddings. The structure of this shaping process, of "making up people", is threefold: it includes 'identification' as a moral-cognitive process of the individuals to "shape their projects-including their plans for their own lives and their conception of the good life" (p. 66). This requires 'labels' which must be available in the public discourse (e.g., man, woman, catholic, jew, new age generation, European, African-American, etc.). These labels express a kind of consensus on how to identify those to whom they should be applied (like stereotypes) (p. 67). People chose a certain role. So the second element of a social identity is the internalization of those labels. The final element is the existence of patterns of behaviour towards such labeled persons (p. 68). The core idea is that identity responses (to be treated as "label") is neither morally wrong in general nor morally neutral. It provides us with an opportunity to self-understanding and taking care for our own live. But it becomes problematic as soon as identification, internalization, and 'treatment as' fall apart and are used in the political discourse to discriminate people (the prevention of this discrimination is the liberal goal of justice). These ideas about identity are not abstract, but experienced, embodied background understandings. Human beings are "embodied agents" (cf. [35, p. 23]), i.e., they perceive, express and articulate themselves with their bodies. The body takes on a special role here: it is not only a means to promote one's interest, but it also mediates experiences and communication. The body bears the imprint and traces of the social and the reverse is also true: social practices are always transmitted through the body (e.g., at work, at performances, and in medical practice) [14]. This special meaning of the body should not be underestimated, especially in the context of medical care and the dying process (see also [30]). When we think about our own death in terms of the ideal of 'a good death', our socio-cultural background is in many ways constitutive of our personal ideals, wishes, and images about how to handle a dying person and care for the weak body. This basic concept of cultural identity as part of our individual identity is explicitly aware of the fact that there are social powers which may restrict the human agent in his development and selfunderstanding. But it emphasizes the aspect of sociality and cultural embeddedness as a necessary and therefore also normatively relevant condition for planning and living one's own life.

To avoid any confusion, I think it is necessary to mention that in medical ethics another conception of personal identity has dominated the discussions. There, special emphasis has been placed on the continuity of the reflexive, psychological 
consciousness (cf. [23]). So for example, persons who suffer from dementia as in Alzheimer's Disease will lose personal identity because their psychological continuity is disrupted due to impairments affecting memory. According to this understanding a moral problem exists in applying a person's advance directive if this person is unable to remember having drawn this document. But this reductionist conception does not help us reflecting on future life plans and on the importance of a socio-cultural framework in which such person is embedded.

\section{Influence of Socio-Cultural Variables on Advance Directives}

In this section, I will review some empirical investigations with the aim of substantiating my argument that culture and social identity is indeed an important determinant of personal attitudes towards end of life decisions. Moreover, these studies provide clues to things we have to keep in mind when interpreting individual wishes. The empirical investigation of how cultural background correlates with end of life preferences will not answer any normative questions as to why we should compose such a living will or what the content should be. But they allow for greater awareness of our own cultural embeddings. Furthermore, they help to identify areas of conflict and misunderstanding (for example: if proxies or doctors don't share the cultural values of the patients). Making implicit cultural assumptions explicit supports patients' self-empowerment and improves communication between patients and families and doctors, patients and families.

Several studies have compared cultures, ethnicities and countries regarding decisions at the end of life and advance directives (cf. [3, 4, 19, 29, 38]). Although I cannot go into too much detail here, I want to illustrate my argument that preferences and practice vary significantly among individuals not only because of personal but also because of cultural framings, for example of belonging to a specific ethnic and religious group. This is-as I tried to argue in the "Introduction"- due to the fact that individuals dedicate themselves to specific communities and refer to shared rules and norms in the way they deal with their body and the medical system. Furthermore, the general arrangement shows that individuals have different, very personal ways of adopting such cultural rules and ways of thinking for example in end of life decisions-which supports Hall's as well as Gidden's argument of understanding identity as a process of negotiation and interpretation.

According to various US American studies, belonging to an "ethnic group" is an important factor in explaining significant differences between the attitudes of patients [2, 3, 9]. For example Mexican-Americans and Korean-Americans participating in the surveys had a significantly greater preference for decisions by family proxies than European-Americans or African-Americans. The former would also more often agree that diagnoses about fatal diseases should be communicated only to family members, but not to the patient [2]. As explanation, the interviewed persons indicated the danger of isolation of the patient, of a psychological shock, and of losing hope. Here the much discussed, culturally dependent weighting of family decisions (instead of self-determination) seems to be relevant. However, in a 
modern world these cultural concepts are not totally valid, and nor can they be seen as monocausally-acting motivations. For example, the study of Morrison (cited in [9]) in a home for the aged in New York showed that many elderly of different ethnic backgrounds esteemed important family centered decisions-but at the same time they themselves did not want to nominate a family member as a proxy. This concrete refusal can result from biographical experiences of personal conflicts in the family. In this case the cultural value of the family per se is shared, but not much trust is put in one's own family.

According to various surveys, Europeans and European-Americans are more likely than other Americans to refuse high-tech medicine at the end of life as "aggressive", while African-Americans (patients as well as physicians) prefer it [2]. Perkins et al. [22], also found in their qualitative interview survey that MexicanAmerican and European-American patients more often than African-Americans voice the wish not to receive life-sustaining treatment. The observation that AfricanAmericans more often wish to receive high tech medicine and life-sustaining treatment is explained among others with the collectively shared self-conception as a group that is often disadvantaged in the system [9]. The enhanced wish for intensive care may result from the background of collectively transmitted fears that their own "group" is deprived of social (and medical) resources and that one is more often perceived as a "second class" person (and patient). Thus, collective experiences with the medical system can also be considered to be culturally rooted: while members of one group direct their mistrust rather against structural discrimination, others are rather skeptical towards an increasing so-called "mechanization".

However, it could be objected that the categorization of ethnicities as 'the one' relevant socio-cultural category of identity is questionable because it is particularly ideologically charged and socially constructed. Turner [37] has also noted that simple ethnic or religious differences should not be used to promote cultural stereotypes. This objection would become especially relevant where categorizations are done by external observers. However, if it is based on the self-assessment of the respondents it can serve as a helpful indication of the cultural frame of reference.

One other factor that is often considered important is religious affinity. It is known that in some religions illness is considered a divine trial that one has to face with discipline (among others in Islam) or as fate decided by God that one must accept (rather a Christian, but partially also a Jewish perspective). However, according to Perkins et al. [22] religious affinity might be less relevant than ethnicity.

As 'culture', according to Taylor is understood as an umbrella term for socially shared values and structures, there should be sensitivity for various cultural secondary aspects. For example, it is reasonable to expect that gender (see also [5]), socio-economic background, social class, and generation could be important factors for understanding differences in values, body conceptions and worldviews. It seems plausible that members of the postwar generation have internalized "declarations of war" against diseases whereas the post-68 generation and late Hippies are rather affected by discourses about naturalness and ecology (cf. to differences between generations regarding values: [13, 32]). 
The results of these various studies suggest that for both empirical research and ethical reflection, it is necessary to consider personal experience as well as their variances and ambivalence within a cultural setting.

It becomes clear that in decisions regarding illness and the end of life various cultural institutions and personal preferences always intertwine: the medical system, family, religion, being a member of a generation, etc., already offer concrete valuations and interpretations of the question "Who are we?". These social institutions have already had an immense influence on an adult-not in the sense of a mono-directional determination, but in a reciprocal process of social and individual interpretation. This existing correlation between socio-cultural factors and individual preferences is often a biographical challenge (see [7]). However, as long as we are conscious persons, we are able to reflect on and guide this interplay between personal and cultural identity.

\section{Between Self-Positioning and Interpretation by Third Parties}

In the case of end of life situations where a patient is not competent or conscious any more, the personal and cultural dimensions of identity are situationally decoupled. This means that the most sensitive aspect in dealing with advance directives is the delegation of the interpretation to a proxy. This is because in the moment of the implementation of an advance directive the affected person herself is no longer able to evaluate the new situation and to express herself. The interpretation of advance directives through third parties is thus more than a necessary evil. It is at the core of the aim and meaningfulness of this instrument for preserving self-interest and putting the patient's will into practice.

The two corresponding procedures of self-positioning and interpretation by third parties could be described as a complex process of hermeneutics. In the context of advance directives, we have to be aware that there are always two different, but not totally independent processes of interpretation: on the one side there is the complex process for the author of an advance directive of finding a personal stance towards one's own decisions in end of life questions and the other side where there are third persons who will interpret the document and act on behalf of their interpretation. This process should be understood as a 'dialectic' process of interpretation and action and not as an objective, deterministic way of 'applying' such a document.

For the author of an advance directive it is an important issue to be aware of the fact that an advance directive could be part of the idea of planning one's own life. This idea of a qualitative identity also presupposes certain stabilities and continuities of our interests, moral attitudes and interpretations. In Taylor's image of a moral-cognitive topography, one can visualize these as 'islands' or 'plateaus'. These stabilities alone allow us to plan our lives and to make decisions. According to Taylor, self-discovery consists of the possibility "to create oneself", of "using the power of imagination" [34, p. 73]. In order to act in an authentic way (in the sense of remaining true to oneself) we must anticipate the future. The drafting of an advance directive can be interpreted as an anticipated self-interpretation-which third persons should fulfill out of respect for the self-determination of other persons. 
This socio-cultural dependency of end of life decisions shows that the decision not to draft an advance directive can also be understood as an expression of a qualitative personal identity. It may be part of one's personal self-conception to rely on the family (or explicitly on others than the family), or on God (as a religious person) or on experts (as someone who trusts in science and medicine). However, it would be advantageous if this trust in a proxy decision were explicitly communicatedotherwise the uncertainty can be expected to lead to many misunderstandings. So there is no duty to draft an advance directive, but there are good reasons from a perspective of the ethics of a good life to consider one. If on the other hand someone conceives autonomy as involving a self-critical reflection on care and concerns about his own body [30], it becomes morally desirable to write an advance directive.

\section{Some Practical Implications}

Recently, many doctors and lawyers have been promoting advance directives. Obviously they offer a moral and juridical relief. Moreover, there is an emerging number of guidelines and blank forms to be found on the internet or promoted by legal bodies. Most of them present simple 'yes or no'-answers based on multiple choice questionnaires. Additionally, the recent drafts often suggest nominating a proxy such as a close relative or friend. This is interesting insofar as it seems that many people still do not know what the function of a health care proxy is (see [27]). Furthermore, the qualitative interview study of Sanders et al. [28] pointed to a moral problem created by such educational material itself: it caused moral confusion and stress within the group of younger patients they interviewed. One can thus conclude that the promotion of advance directives without reflection on the broader meaning for the individual and their surroundings provokes new problems.

The point I want to make here is that end of life decisions are moral dilemmas concerning most people (in industrialized countries). Once we become aware that decisions pro or contra life sustaining treatment are part of our own life plan we pose the question "What person am I and what is my idea of a good life?". Moreover, this kind of internal moral inquiry is bound up with the meaning of personal and social identity, as I have argued above. With regard to the concrete process of drafting an advance directive, we have to answer questions like: (a) Do I want to be the one who 'plans' my life or death in the long-term or should I rely on others (on God etc.)? (b) Do I consider it wise and morally desirable to commit myself now to how one could and should treat me in anticipated future situations (does it relax me or will it induce psychological stress)? (c) Who (of my family, my friends) do I really trust to act for me as a proxy and to interpret my document?

Today, only few structures exist (or in most countries none at all) for providing personnel trained to inform and counsel lay people in these difficult questions. Furthermore, answers to these questions are required to consider cultural differences if, as I hope to have shown, the answers to questions about identity and discursive practice depend on social expectations and cultural 'labels' (someone identifies himself with). The latter we should consider as a chance rather than a risk. 
We need more structures for people to deliberate (and not to force them) on whether they want to draft an advance directive and if so, with what scope and content. The theoretical considerations about the interplay between self-interpretation, cultural assumptions and likely interpretation by third parties may allow a critical view on the recent practice: more needs to be done than just providing questionnaires and information material if we want to protect and strengthen the autonomy of the patient.

There are at least three categories of people we have to consider: first, those who share the idea of being open about one's own death and the wish to control it with an advance directive. Second, those who are aware of being a part of a so called 'deathdenying' society and explicitly avoid thinking or talking about negative ideas such as illness and death. Third, persons who are ambivalent and don't want to make a decision now.

With regard to the clinical situation I suggest there is a need for improvements on three levels: first, we need more processual communication and deliberation instead of unfocused dissemination of material and standard questionnaires. First of all, people should not be put under pressure to draft an advance directive but should be provided with information regarding the aims and concrete problems of such a document. This includes reflecting on the role of a proxy and the likelihood of new situations which will need further interpretation. It seems that many people fear the dictatory use of such advance directives (very likely regarding the withdrawal of life-sustaining treatment) even if they are no longer appropriate to the medical situation (see [27]). Here, the importance of interpretation and the proxy comes into play. The aim of such a deliberating process should be to arrive at a standpoint as a basis for deciding what to do, and this does not have to mean actually drafting an advance directive.

Second, the role of proxies should be well-defined and legally binding. It needs to be considered, however, that in practice this often constitutes a moral and psychological burden for the surrogate decision maker. They themselves will be in need of persons with whom they may deliberate about the right interpretation. This kind of support is still missing and could be provided not only by health care providers but also by social workers and philosophically guided councellors.

Third, we need more empirical evaluation of the current process that defines how advance directives are used, modified and assessed by patients and lay people. Here, a special focus should be on the various sub-categories of cultural impacts. Additionally, we need more awareness of how talking about one's own death differs culturally. There are, indicated by the few studies we have, several forms of expression and not just one. But the recent medico-juridical discourse tends to support standardization and legal terminology rather than diversity. It seems very plausible, however, that we need various alternative methods to express one's identity and preferences with respect to end of life decisions. In support of this argument, various authors have shown that above all narrative approaches and biographical anecdotes and personal episodes provide important information [29] which is central for the interpretation of new situations. 
Acknowledgments I would like to thank the participants of the Workshop: "Self, Identities and Bioethics" held in Linköping, Sweden in May 7-9, 2008 for fruitful comments on an earlier version as well the two anonymous reviewers for helpful remarks. I thank Benjamin Waters (Berlin) very much for his help in editing language.

Open Access This article is distributed under the terms of the Creative Commons Attribution Noncommercial License which permits any noncommercial use, distribution, and reproduction in any medium, provided the original author(s) and source are credited.

\section{References}

1. Appiah, K. A. (2005). The ethics of identity. Princeton and Oxford: Princeton University Press.

2. Blackhall, L. J., Murphy, S. T., Frank, G., Michel, V., \& Azen, S. (1995). Ethnicity and attitudes toward patient autonomy. Journal of the American Medical Association, 274, 820-825. doi: 10.1001/jama.274.10.820.

3. Candib, L. M. (2002). Truth telling and advance planning at the end of life: Problems with autonomy in a multicultural World. Families, Systems \& Health, 20(3), 213-228. doi:10.1037/h0089471.

4. Carrese, J. A., \& Rhodes, L. A. (2000). Bridging cultural differences in medical practice: The case of discussing negative information with Navajo patients. Journal of General Internal Medicine, 15, 9296. doi:10.1046/j.1525-1497.2000.03399.x.

5. Conradi, E., Biller-Andorno, N., Boos, M., Sommer, C., \& Wiesemann, C. (2003). Gender in medical ethics: Re-examining the conceptual basis of empirical research. Medicine, Health Care, and Philosophy, 6, 51-58. doi:10.1023/A:1022514821765.

6. Fagerlin, A., \& Schneider, C. E. (2004). Enough: The failure of the living will. The Hastings Center Report, 34(2), 30-42. doi:10.2307/3527683.

7. Giddens, A. (1987). Social theory and modern sociology. Stanford, CA: Stanford University Press.

8. Giddens, A. (1991). Modernity and self-identity. Cambridge: Polity Press.

9. Giger, J. N., Davidhizar, R. E., \& Fordham, P. (2006). Multi-cultural and multi-ethnic considerations and advance directives: Developing cultural competency. Journal of Cultural Diversity, 13(1), 3-9.

10. Habermas, J. (1991). Erläuterungen zur Diskursethik [Explanations of discourse ethics]. Frankfurt a.M.: Suhrkamp.

11. Haker, H. (1999). Moralische Identität. Literarische Lebensgeschichten als Medium ethischer Reflexion [Moral identity: Literal stories of life as mean for ethical reflection]. Tübingen: Francke Verlag.

12. Hall, S. (1996). Who needs 'Identity'? In S. Hall \& P. du Gay (Eds.), Questions of cultural identity (pp. 1-18). London: SAGE.

13. Hallenbeck, J., \& Goldstein, M. A. (1999). Decisions at the end of life. Cultural considerations beyond medical ethics. Generation, 23(1), 24-29.

14. Hancock, P., Hugges, B., Jagger, E., et al. (2000). The body culture and society. An introduction. Buckingham, Philadelphia: Open University Press.

15. Helman, C. G. (2001). Culture, health and illness. Oxford: Butterworth.

16. Hurka, T. (1993). Perfectionism. New York: Oxford University Press.

17. Hursthouse, R. (2007). Virtue ethics. Stanford encyclopaedia of philosophy, http://plato.stanford. edu/entries/ethics-virtue/.

18. Krämer, H. (1992). Integrative Ethik [Integrative ethics]. Frankfurt a.M., Suhrkamp.

19. Leichtentritt, R. D., \& Rettig, K. (1999). Meanings and attitudes towards end-of-life preferences in Israel. Death Studies, 23, 323-358.

20. National Ethics Council. (2005). Opinion report on advance directives. Berlin: National Ethics Council.

21. Oorschrot, B., \& Simon, A. (2007). Importance of the advance directive and the beginning of dying process from the point of view of German doctors and judges dealing with guardianship matters: Results of an empirical survey. Journal of Medical Ethics, 32, 623-626. doi:10.1136/jme.2005. 015032 . 
22. Perkins, H. S., Geppert, C., Gonzales, A., Cortez, J. D., \& Hazuda, H. P. (2002). Cross-cultural similarities and differences in attitudes about advance care planning. Journal of General Internal Medicine, 17(1), 48-57. doi:10.1046/j.1525-1497.2002.01032.x.

23. Quante, M. (2002). Personales Leben und menschlicher Tod. Personale Identität als Prinzip der biomedizinischen Ethik [Personal life and human death: personal identity as bioethical principle]. Frankfurt a.M.: Suhrkamp.

24. Rawls, J. (1983). A theory of justice. Oxford, Melbourne: Oxford University Press.

25. Rosa, H. (1998). Identität und kulturelle Praxis: Politische Philosophie nach Charles Taylor [Identity and cultural practise: Political philosophy after Charles Taylor]. Frankfurt a.M.: Campus.

26. Rurup, M. L., Onwuteaka-Philipsen, B. D., Van der Heide, A., et al. (2006). Frequency and determinants of advance directives concerning end-of-life care in The Netherlands. Social Science \& Medicine, 62, 1552-1563. doi:10.1016/j.socscimed.2005.08.010.

27. Sahm, S., Will, R., \& Hommel, G. (2005). Attitudes towards and barriers of writing advance directives amongst cancer patients, health controls, and medical staff. Journal of Medical Ethics, 31, 437-440. doi:10.1136/jme.2004.009605.

28. Sanders, C., Rogers, A., Gatey, C., \& Kennedy, A. (2008). Planning for end of life care within lay-led chronic illness self management ttraining: This significance of 'death awareness' and biographical context in participants accounts. Social Science \& Medicine, 66, 982-993. doi:10.1016/j.socscimed. 2007.11.003.

29. Sass, H. M., Bonkovsky, F. O., Akabayashi, A., Kielstein, R., \& Olick, R. S. (1996). Advance health care documents in multicultural perspectives. Jahrbuch für Recht und Ethik, 4, 465-508.

30. Schicktanz, S. (2007). Why the way we consider the body matters: Reflection of four bioethical perspectives of the human body. Philosophy, Ethics and Humanities in Medicine, 2, 1, 30, 1-12, http://www.peh-med.com/content/2/1/30 (open access).

31. Schicktanz, S., Schweda, M., \& Franzen, M. (2008). 'In a completely different light'?-The role of being affected for epistemic perspectives and moral attitudes of patients, relatives and lay people. Medicine, Health Care, and Philosophy, 11, 57-72. doi:10.1007/s11019-007-9074-2.

32. Steverink, N., Westerhof, G. J., Bode, C., \& Dittmann-Kohli, F. (2001). The personal experience of aging, individual resources, and subjective well-being. Journal of Gerontology, 56B(6), 364-373.

33. Taylor, C. (1989). Sources of the self. The making of modern identity. Cambridge: Harvard University Press.

34. Taylor, C. (1991). The malaise of the modernity. Toronto: Anansi.

35. Taylor, C. (1995). The validity of transcendental arguments. In C. Taylor (Ed.), Philosophical arguments (pp. 20-33). Cambridge: Harvard University Press.

36. Taylor, C. (1995). Cross-purposes. The liberal-communitarian debate. In C. Taylor (Ed.), Philosophical arguments (pp. 181-203).

37. Turner, L. (2005). From the local to the global. Bioethics and the concept of culture. The Journal of Medicine and Philosophy, 30, 305-320. doi:10.1080/03605310590960193.

38. Voltz, R., Akabayashi, A., Reese, C., Ohi, G., \& Sass, H. M. (1998). End-of-life decisions and advance directives in palliative care. A cross-cultural survey of patients and health-care professionals. Journal of Pain and Symptom Management, 16(3), 153-162. doi:10.1016/S0885-3924 (98)00067-0. 